\title{
ROLE OF MEDICAL COLLEGES IN TB CONTROL IN INDIA
}

\author{
Anand D. Meundi ${ }^{1}$
}

${ }_{1}^{1}$ Professor, Department of Community Medicine, Academy of Medical Sciences, Pariyaram, Kannur.

\section{ABSTRACT}

In the present time medical colleges are facing the arduous task of demonstrating that they respond to health needs of the patients, families, communities and the nation at large. A substantial proportion of patients with Tuberculosis (TB) are managed at medical colleges (Mostly situated in urban/semi-urban areas) across the country and consequently the medical colleges occupy a key position with immense potential for involvement with the Revised National Tuberculosis Control Programme (RNTCP). Undeniable reasons why medical colleges must act as flag bearers of RNTCP are explained. The unique initiative of formally involving medical colleges in RNTCP by way of creating zonal task force mechanism, the contribution of medical colleges to TB control and the future direction and challenges are elaborated.

\section{KEYWORDS}

RNTCP, Medical College, Tuberculosis, Control.

HOW TO CITE THIS ARTICLE: Meundi AD. Role of medical colleges in TB control in India. J. Evolution Med. Dent. Sci. 2016;5(52): 3462-3464, DOI: 10.14260/jemds/2016/798

\section{INTRODUCTION}

Provision of health care service is the second most important function of a medical college besides creation of the health care manpower. Quality, equity, relevance and cost-effectiveness are the four universally acknowledged characteristics of health care. In the present time, medical colleges are facing the arduous task of demonstrating that they respond to health needs of the patients, families, communities and the nation at large. This calls for identification of community-needs, adaptation of the medical colleges' programmes to meet them and provide evidence that the community has benefitted from these interventions. ${ }^{1}$

Undoubtedly, control of TB (Tuberculosis) is one of the major challenges faced by health care sector in India in general and medical college providers in particular. More adults die due to TB in India than any other infectious disease. ${ }^{2}$ An estimated 2.2 lakh persons die due to TB in India annually. ${ }^{3}$ The Revised National TB Control Programme (RNTCP) was piloted by Government of India (GOI) between 1993 and 1996. Further, RNTCP expanded to cover the entire Indian population and achieved complete coverage by 2006. Nearly, 50 percent of the retreatment cases notified under RNTCP are treated in other sectors before reaching RNTCP suggesting inadequate treatment and possible amplification of drug resistance. The most serious challenge to TB control is in urban areas. Urban primary health care systems tend to be weaker and private health care predominates. MDR-TB (Multi-drug resistant TB)/XDR-TB (Extensively drug resistant TB) occurs due to misuse of anti-TB drugs and interrupted treatment, largely in the private sector and then can be spread in the community unless it is correctly diagnosed and treated. ${ }^{4}$

Interestingly, a substantial proportion of patients with TB are managed at medical colleges (Mostly situated in urban/semi-urban areas) across the country.

Financial or Other, Competing Interest: None.

Submission 26-04-2016, Peer Review 09-06-2016,

Acceptance 14-06-2016, Published 30-06-2016.

Corresponding Author

Dr. Anand D. Meundi,

Professor, Department of Community Medicine,

Academy of Medical Sciences,

Pariyaram, Kannur.

E-mail:anandmeundi@yahoo.com

DOI: $10.14260 /$ jemds $/ 2016 / 798$
In the year 2014-2015, about 2,81,719 TB cases (Pulmonary and extra-pulmonary) cases were diagnosed by medical colleges in India and these medical colleges contribute to about $20 \%$ of the total cases registered under RNTCP. ${ }^{3}$ Consequently, the medical colleges occupy a key position with immense potential for involvement with RNTCP. Therefore, there is a pressing need for all medical colleges to advocate and practice DOTS (Directly observed treatment short course) strategy, which provides the best opportunity for cure of TB patients. There are several reasons why involvement of medical colleges in RNTCP is of undeniable importance:

a. Being tertiary care medical centers, large number of patients seek care from the medical colleges.

b. The role of medical college faculty in TB control as key opinion leaders and role models for practicing physicians cannot be overemphasized.

c. As teachers of medicine, imparting knowledge, skills and shaping the attitude of medical students is vital to creation of a responsible healthcare workforce. Teachers are role models for the students, as they require to possess the range of competencies expected from the graduates. Their use of best practices in educational methodologies applied to medicine and healthcare is an absolute requirement. 5

d. Medical colleges have the diagnostic facilities for ExtraPulmonary TB (EPTB), Human Immunodeficiency Virus (HIV)-TB co-infection, multidrug-resistant TB and extensively drug-resistant TB (M/XDR-TB), as they often have the expertise and infrastructure, and lastly

e. From the social accountability viewpoint, the medical colleges must go one step beyond just taking specific actions through its education, research and service activities to meet the priority health needs of society. They must also work collaboratively with governments, health service organizations and the public to positively impact people's health and must be able to demonstrate this by providing evidence that their work is relevant, of high quality, equitable, cost-effective. ${ }^{5}$

Recent Scale-up of Efforts to involve Medical Colleges in Implementation of RNTCP

In order to harness the potential of involving medical colleges in TB control, the RNTCP for the first time in the world 
conceived and implemented the unique experiment of involving the academicians who constitute the medical college faculty in the National programme for TB control. The first National consensus conference on TB was held in New Delhi in 1997, followed by two meetings in 2001 at the National Tuberculosis Institute (NTI), Bengaluru and the All India Institute of Medical Sciences (AIIMS), New Delhi. In these meetings, recommendations were made to consider medical colleges as an integral part of the RNTCP. As per these recommendations, it was envisioned that medical colleges will offer RNTCP diagnostic and treatment services, teach and carry out advocacy about RNTCP and participate in implementation and monitoring of the programme. Professors in these medical colleges recognized and accepted RNTCP as a dynamic TB control programme with potential for a "Remarkable success" in TB control in India; thereby, they put forth their unflinching commitment to the Programme. ${ }^{2}$

The October 2002, National Level Workshop of Medical Colleges at AIIMS, New Delhi, was instrumental in developing the structure and processes required for the effective nationwide participation of medical colleges in the Programme. Seven medical colleges located in the different zones of the country at New Delhi, Chandigarh (North), Jaipur, Mumbai (West), Kolkata (East), Vellore (South) and Guwahati (NorthEast) were identified as nodal centers and were requested to lead the initiative of participating in the Programme. A Task Force mechanism at the National, Zonal and State level was established. Subsequently, there were consensus workshops in the States with medical colleges, which further documented the exact mechanisms for collaboration. This formed the basis for GOI's policy of involving medical colleges in TB control. ${ }^{2}$ Zonal division of States for this activity comprised five States in the East, eight each in the North-East and the North, five in the South and five States in the West zone. ${ }^{2}$ Currently, there are six zones - North with 8 states, West with 5 states, East with 5 states, North-east with the north-eastern states, South 1 with 3 states and South 2 with 3 states. $^{3}$ The State Task Force undertook the necessary activities to facilitate establishment of Directly Observed Treatment (DOT) centers as well as other activities in all the medical colleges in the respective States. Over the subsequent years, wider interaction with medical colleges has occurred through a series of sensitization seminars, training of medical college faculty staff at Central TB Institutes and National and Zonal Level Workshops. ${ }^{2}$ By the end of December 2015, 363 of about 390 (93\%) medical colleges were involved in the RNTCP implementation. ${ }^{3}$

\section{Contribution of Medical Colleges to RNTCP in the Recent Past}

An article published in the IJTLD (International Journal of Tuberculosis and Lung Disease) has documented the outcome of the scale-up of the RNTCP's public-private mix. During this scale up effort, it was evident that medical colleges contributed to a large chunk of referral, diagnosis, NSP (New Sputum Positive) case notification and treatment of Tuberculosis. The number of cases notified per staff member was much higher for Medical College Hospitals and State Level Public Health Facilities than for the public sector facilities outside the purview of the state government and private health facilities. ${ }^{6}$

The National Task Force has been the voice of the collective opinion of academicians in medical colleges and has contributed to articulating critical policy issues such as ensuring that teaching and training regarding RNTCP is imparted to students and interns, making provision of infrastructural facilities like DMC (Designated Microscopy Center) and DOT (Directly Observed Treatment) center at medical colleges mandatory by Medical Council of India (MCI), rational use of fluoroquinolone antibiotics in the treatment of respiratory tract infections and airborne infection control policy among others. ${ }^{2}$

To facilitate conduct of Operational Research (OR), State OR committees were formed in all the States with medical colleges and Zonal OR committees were formed in all the six zones. The OR Committees sanction funding for research projects. The RNTCP also instituted a consolidated grant amount of Rs. 30,000 for postgraduate thesis conducted on OR topics relevant to the Programme needs; at least one postgraduate thesis grant per medical college per year is awarded.

Medical colleges have been actively involved in the HIV-TB cross-referral mechanism. The medical colleges provide facilities for CD4+/CD8+ count testing and provision of antiretroviral therapy through Anti-Retroviral Treatment (ART) centers for HIV-TB co-infection. Several medical colleges in the country have already obtained accreditation for their laboratories for culture and drug-susceptibility testing under RNTCP. $^{2}$

\section{Challenges and Future Directions: Moving Closer to the Light at the End of the Tunnel}

In spite of the elaborate mechanisms in place to involve medical colleges in RNTCP, there is a potential threat that the involvement may eventually decline or just remain on paper. In a study carried out by Quazi TA et al in 2012 in three medical colleges of West Bengal and Meghalaya, nearly two-thirds of probable or confirmed TB cases identified in the Departments of Radiology, Microbiology and Pathology were not referred to RNTCP. The authors rightly recommend that training of health care providers in medical colleges be combined with a surveillance system for TB cases at all departments. ${ }^{7}$ It is vital that all cases of TB diagnosed in medical colleges are notified to RNTCP and offered DOTS treatment to ensure continuous provision of anti-TB drugs, proper supervision and follow-up.

Therefore, the need of the hour is to sustain the momentum gained and push medical college involvement forward by continuing coordination and communication more frequently and more vociferously by way of repeat sensitization and appraisal programmes. It must be understood that "Consensus" is the keyword in eliciting cooperation of providers in medical colleges. It must also be acknowledged that all skepticism about RNTCP can be convincingly addressed and these issues should not jeopardize the united march against TB. There is a need to demand implementation of RNTCP at all medical colleges by the accrediting, permitting and governing bodies.

As proposed by Arora $V$ et al, establishing a single window information system for TB diagnosis and treatment and referring the patients back to private sector after completion of treatment might instil confidence amongst the private physicians about RNTCP. 8

There are two other issues that need attention. Firstly, the volume of operational research in the area of TB control remains dismal. This can be addressed by providing attractive funding and clear-cut guidelines with specified time-line so as 
to attract interested faculty members from medical colleges to take up research studies. Second, there is a need to awaken concern about airborne infection control and its overarching effect on TB transmission in all health care settings in general and in Medical College Facilities in particular. This calls for creation of awareness, implementation of good practices and relevant research.

\section{REFERENCES}

1. Boelen C, Woollard R. Social accountability: the extra leap to excellence for educational institutions. Med Teach 2011;33(8):614-9.

2. Sharma SK, Mohan A, Chauhan LS, et al. Contribution of medical colleges to tuberculosis control in India under the revised national tuberculosis control programme (RNTP): lessons learnt \& challenges ahead. Indian J Med Res 2013;137(2):283-94.

3. Central TB division. TB India 2016. Revised national TB control programme. Annual status report. Directorate general of health services, ministry of health and family welfare, government of India. New Delhi. 2016.
4. Sachdeva KS, Kumar A, Dewan P, et al. New vision for revised national tuberculosis control programme (RNTCP): universal access-reaching the un-reached. Indian J Med Res 2012;135(5):690-4.

5. Boelen C, Dharamsi S, Gibbs T. The social accountability of medical schools and its indicators. Educ Health 2012;25(3):180-94.

6. Lal SS, Sahu S, Wares F, et al. Intensified scale-up of publicprivate mix: a systems approach to tuberculosis care and control in India. Int J Tuberc Lung Dis 2011;15(1):97-104.

7. Quazi TA, Sarkar S, Borgohain G, et al. Are all patients diagnosed with tuberculosis in Indian medical colleges referred to the RNTCP? Int J Tuberc Lung Dis 2012;16(8):1083-5.

8. Arora V, Jaiswal AK, Gupta S, et al. Implementation of RNTCP in a private medical college: five years' experience. Indian J Tuberc 2012;59(3):145-50. 